\title{
Nursing and medical staff's experiences of simulation education
}

\author{
Mari Helena Salminen-Tuomaala*1, Pasi Jaskari ${ }^{2}$, Sami Perälä ${ }^{3}$, Christina Rouvala ${ }^{4}$ \\ ${ }^{1}$ Seinäjoki University of Applied Sciences, School of Health Care and Social Work, Finland \\ ${ }^{2}$ Seinäjoki Vocational Education Centre, Seinäjoki, Finland \\ ${ }^{3}$ South Ostrobothnia Health Technology Development Centre EPTEK, Seinäjoki, Finland \\ ${ }^{4}$ Seinäjoki Central Hospital, Seinäjoki, Finland
}

Received: July 7, 2017

DOI: $10.5430 /$ cns.v5n $4 p 73$
Accepted: August 30, 2017

Online Published: September 12, 2017

\begin{abstract}
Objective: The purpose of the research was to describe nursing and medical staff's knowledge of simulated learning and their experiences of the usefulness of simulation education in one hospital district in Finland. The research aimed at producing user-oriented knowledge to be used in the development of multiprofessional simulation pedagogical continuing education. The study is part of a larger research project, whose purpose is to build up a multiprofessional simulated learning environment for a network of partners. They involve a university of applied sciences, a vocational education center, a health technology development center and a hospital district.

Methods: Data were collected using a Web-based survey tool between December 1, 2016 and January 13, 2017. The questionnaire contained both quantitative $(n=24)$ and qualitative $(n=3)$ items. This article deals with quantitative data only. Data was analyzed using SPSS Statistics for Windows 23. The response rate was $28 \%(\mathrm{n}=125)$.

Results: Both nursing and medical staff found that simulation education had been useful for the development of their theoretical and practical competence. Some statistically significant differences were discovered between various age and professional groups. Conclusions: As a conclusion, nursing and medical staff in this hospital district need more information about simulation education and simulated learning environments. The knowledge produced in this study can be used in planning multiprofessional simulation pedagogical continuing education. Simulation pedagogy can be especially useful when practicing teamwork and interaction in acute, recurring and infrequent care situations.
\end{abstract}

Key Words: Simulation education, Professional development, Learning environment, Nursing staff, Doctor

\section{INTRODUCTION}

The use of simulation is becoming increasingly common in the education of healthcare professionals. Simulation allows participants to practice safely across the full breadth of patient care. It can be used, for example, as a response to the need to learn adverse event management or new technologies. ${ }^{[1]}$ Simulation-based education can also have an important role in promoting teamwork skills. ${ }^{[2]}$ It has been internationally recognized that joint training should be offered to nursing and medical staff to help them achieve a combination of interdisciplinary competence and to facilitate the synchronization of tasks. Simulation can be a useful method when striving to meet patients' increasingly complex healthcare needs and to provide patient-centered holistic

\footnotetext{
* Correspondence: Mari Helena Salminen-Tuomaala; Email: Mari.Salminen-Tuomaala@ seamk.fi; Address: Seinäjoki University of Applied Sciences, School of Health Care and Social Work, Finland.
} 
care. ${ }^{[3,4]}$ Together with other action learning methods, simulation can be an important part of multiprofessional continuing education programs, designed to increase nurses' and doctors' collaboration and mutual appreciation. ${ }^{[5]}$

This study is part of larger research project, whose purpose is to build up a multiprofessional simulated learning environment for a network of partners in Finland. They involve a university of applied sciences, a vocational education center, a health technology development center and a hospital district that provides specialized medical services.

\section{BACKGROUND}

In health care, simulations are used for assessment, research, health system integration and education, ${ }^{[6]}$ which is the focus of this study. Simulation enables learning in a nearly authentic, clinical environment safely, provided that the learning aims, content and setting have been carefully planned. Simulation can be defined as imitation of real-life activity, based on clearly defined learning aims and implemented in as genuine a context as possible. Simulation pedagogy aims at an immersive, experiential and action-based learning experience and at the development of specific competencies. ${ }^{[7]}$

Simulation-based learning can occur through workshops, virtual simulation or full scale simulations that allow full immersion. Participants can be engaged in case studies or learn individual tasks, using simulators or simulation software as assistive tools. All simulators share the attribute of being interactive. For example, a participant's actions cause changes in the simulator operations, such as a simulation dummy's vital functions. The changes are visible in the simulator controls operated by the facilitator, while the learner is expected to react to the changes in an appropriate manner ${ }^{[8]}$ It has been pointed out that it is not necessary to provide a high technology learning environment to practice high quality simulation. However, the learning of skills or procedures must be contextualized. ${ }^{[6]}$ It is even possible for the facilitator to assume a patient role, which renders the situation more authentic.

Simulations can be said to consist of three stages. The first stage, preparing, involves creating a scenario, setting learning objectives, assigning learner and observer roles and briefing the participants. The second stage is the actual simulation activity. In the third stage, the learners, observers and facilitators reflect on the situation together. ${ }^{[8]}$ This debriefing is essential, as personal reflection and feedback are a prerequisite for profound learning experiences and professional development. ${ }^{[9]}$

Simulation has typically been used to support learning of commonly performed procedures or acute situations and to orient or assess new trainees or employees. Simulation can be of great benefit when preparing participants for rare critical incidents. ${ }^{[6]}$ Simulation pedagogy can also be used to develop what might be called more generic competencies, for example management and teamwork skills, overall management of patient care and counseling. ${ }^{[9]}$ It can help build up confidence in collaborative practice and team training. ${ }^{[6]}$ The ability to work as an effective team is a vital skill; in emergency medicine, for example, failing team work is often presented as a cause of adverse events. ${ }^{[2]}$

The use of simulation in healthcare education has the obvious advantage of minimizing risks to patients; learners can safely practice even complex and demanding situations. It has been suggested that simulated learning environments could be used for all clinical skill development. A simulated environment is safe and structured; it allows learners to receive constant feedback and support. All the patient safety requirements can easily be met. ${ }^{[10,11]}$ Some studies argue that in situ simulations are more effective, while others reveal that the setting might not affect the learning results. ${ }^{[12]}$ It has also been suggested that simulation has some further pedagogical benefits over other training modalities. It may, for example, lead to learning faster and that it has been found effective when used in addition to other methods. Participants can practice skills repeatedly. As simulated scenarios replace real patients and situations, they can be created and adapted fast at any time to meet contemporary learning requirements. At least in some approaches, learner performance can be more objectively measured. A simulated situation also allows the focus to be completely on the learning needs and there is evidence that the skills learnt are transferred to clinical settings. Moreover, simulation training can be provided at relatively low cost. ${ }^{[6]}$

Although a significant body of international literature exists on the use of simulation, in Finland nursing and medical staff's experiences of multi-professional simulation-based learning have not yet been studied adequately. The experiences reported on internationally have been positive, for example in the areas of acute and intensive care, anesthesiology and perioperative nursing and obstetrics. ${ }^{[13-19]}$ According to studies conducted so far, simulated learning can improve both professional competencies and patient care outcomes. ${ }^{[20-22]}$ Innovative action-based learning methods are required to serve practicing professionals, who need to improve their interaction, co-operation and teamwork skills or want to learn to better manage clinical situations. It would seem that simulation-based education can lead to better learning results than traditional teaching methods. ${ }^{[23-26]}$ It can also increase learners' confidence in their skills. ${ }^{[27,28]}$ Finally, successful teamwork between professionals affects patients' 
experience of the quality of the overall care delivered. ${ }^{[29]}$

\section{MethodS}

\subsection{Study purpose and aim}

The purpose of the study was to describe nursing and medical staff's knowledge of simulated learning and their experiences about the usefulness of simulation education in one hospital district in Finland. The purpose was to produce user-oriented knowledge that can be used to develop multiprofessional simulation pedagogical continuing education further.

\subsection{Research questions}

The study sought to answer the following questions:

(1) What kind of knowledge do nursing and medical staff have of simulation education and simulated learning environments?

(2) What kind of experiences have nursing and medical staff had of the usefulness of simulation education?

\subsection{Target group and data collection}

The target group for this study consisted of 450 healthcare professionals working for a hospital district. The response rate was $28 \%(\mathrm{n}=125)$. Respondents were registered nurses (84), practical nurses (10), emergency medical technicians (5) and doctors (26). Data were collected using the Webropol survey tool between December 1, 2016 and January 13, 2017. The Webropol survey tool was chosen because of its flexible use online. It is an online analysis and survey tool, which enables sending of electronic questionnaires and conducting both quantitative and qualitative analysis of the data. ${ }^{[30]}$ Prior to the study, the questionnaire was tested with a small group of respondents. Information about the study was published on the hospital district's internal website. Those belonging to the target group also received a message in their personal workplace e-mail containing an information sheet, letter of invitation and a link to the online questionnaire. The recipients were informed that their participation was voluntary and that their anonymity would be protected throughout the research process. Ward managers were requested to remind staff of the study, but to ensure that no pressure was exerted on them, they were never asked if they had actually done so. The survey tool proved to be effective; the response was fast and data was easily imported into the SPSS through Excel. ${ }^{[31]}$

The questionnaire was based on a systematic literature review and developed for this study specifically. It contained both quantitative and qualitative items. This article deals with quantitative data only, gleaned from responses to 24 questions, 18 of which were Likert type items. The questionnaire also included background questions including gender,

Published by Sciedu Press age, education, profession and length of work experience. Respondents' knowledge of simulated learning and learning environments and their opinions of the usefulness of simulation education in learning knowledge, skills and interaction were studied using Likert type questions. They were asked to rate their agreement on a five-point scale: $1=\operatorname{good} / \mathrm{a}$ lot; 2 = quite good/quite a lot; 3 = moderate/moderately; $4=$ quite weak/quite little and $5=$ weak, little. For example, Simulation training strengthens teamwork skill 1, 2, 3, 4, 5.

Finally, the questionnaire included three open questions not discussed in this analysis. The qualitative results have been published in another article.

\subsection{Data analysis}

Data was analyzed using statistical methods and SPSS Statistics for Windows 23. Respondents were classified into five groups according to age (under 30, 30-39, 40-49, 50-59 and over 60 years old) and seven groups according to work experience (under 5, 5-10, 11-15, 16-20, 21-25, 26-30 and over 30 years) (see Table 1). The purpose was to investigate if any association existed between gender/age/education/profession and work experience variables and the reported knowledge of simulation education/simulated learning environments and the experienced usefulness of simulation education. Data was described using frequencies, percentages and means. Cross tabulation was used to assess the relationship between variables. The distributions were skewed, so the non-parametric Mann-Whitney U Test and Kruskal-Wallis test were used. Nonparametric statistics make no assumptions about the probability distributions of the variables. Statistical significance was set at $p<.05 .^{[32]}$

\subsection{Research ethics}

The investigators found the topic important and ethically justified, because up until now, little multiprofessional simulation-based continuing education has been provided for medical and nursing staff. The results can benefit respondents themselves, their supervisors and ultimately, patients. The ethical guidelines of the National Advisory Board on Research Integrity ${ }^{[33]}$ were observed throughout the study. Permission to conduct the study was granted by the hospital district. The hospital district ethics committee approval was not required, because the study only involved employees.

Nursing and medical staff were informed of the purpose and voluntary nature of the study on the hospital district internal website and by means of email. They responded anonymously through a Webropol link. It was ensured that individual respondents could not be identified. The electronic questionnaire was protected through a password and the responses were stored into a database secured with a password 
to ensure confidentiality and accuracy of the data. ${ }^{[32]}$

\subsection{Reliability}

The questionnaire was pre-tested for reliability and validity. The members of the test group found the items on the questionnaire logical, clear and comprehensible. The low response rate $(28 \%)$ may be due to the Webropol survey as a data collection method, the length of the questionnaire and timing of the study during winter holiday season. In addition, simulation-based education may have been an unfamiliar topic for some older employees. Electronic questionnaires have been found to yield lower response rates than printed questionnaires. ${ }^{[34,35]}$ Closed ended questions may have limited the information from the respondents, thereby causing low validity of the data. The small sample size limits the generalizability of the results. The number of responses $(n=125)$ can, however, be considered adequate for statistical analysis, considering the total number of employees in the hospital district.

\section{Results}

\subsection{Demographic data}

As shown in Table 1, out of the 125 participants, $80 \%$ were members of nursing staff and $20 \%$ doctors. A higher percentage of the respondents were female (women $68 \%$, $\mathrm{n}=85$; men $32 \%, \mathrm{n}=40$ ). The age range was $24-66$ years. The largest group of the respondents (42\%) held a Bachelor's degree from a university of applied sciences, whereas $21 \%$ had graduated from a shorter program in a higher vocational education institution, currently phased out. In addition, 26\% of the respondents had a university education and $6 \%$ a lower vocational education. The respondents were fairly evenly distributed as regards work experience; $52 \%$ of them had less than 16 years and $47 \%$ had 16 or more years of work experience. The majority, $82 \%$, had at some stage participated in simulation education.

\subsection{Nursing and medical staff's knowledge of simulation as a teaching method}

Figure 1 showed that the greatest group in both women (31\%) and men $(39 \%)$ found that their knowledge of simulation as a teaching method was moderate. It can also be noted that more than a fourth of women $(26 \%)$ and over a third of men (34\%) considered their knowledge quite weak. Approximately one third of the women (34\%), however, rated their knowledge as good or quite good, whereas in men, the corresponding proportion was only $16 \%$. Women assessed their knowledge of simulated teaching higher than men $(p=.106)$. The difference can be regarded as possibly significant. Comparison by age using the Kruskal-Wallis test revealed a statistically significant difference $(p=.001)$ be- tween the 30-39-year-old and 50-59-years-old nursing staff members: the older age group rated their knowledge of simulation teaching as better than the 30-39-year-old respondents. The result is noteworthy, considering that simulation had not been used in healthcare education at the time of their studies.

Table 1. Demographic data on respondents

\begin{tabular}{|c|c|c|}
\hline & $\bar{n}$ & $\%$ \\
\hline \multicolumn{3}{|l|}{ Age } \\
\hline$\bullet<30$ & 22 & 18 \\
\hline - 30-39 & 35 & 28 \\
\hline • 40-49 & 28 & 22 \\
\hline • 50-59 & 32 & 26 \\
\hline$\bullet>60$ & 8 & 6 \\
\hline \multicolumn{3}{|l|}{ Gender } \\
\hline - Female & 85 & 68 \\
\hline - Male & 40 & 32 \\
\hline \multicolumn{3}{|l|}{ Education } \\
\hline - Lower vocational & 8 & 6 \\
\hline - Higher vocational & 26 & 21 \\
\hline - University of applied sciences & 53 & 42 \\
\hline - University & 33 & 26 \\
\hline \multicolumn{3}{|l|}{ Profession } \\
\hline - Doctor & 26 & 21 \\
\hline - Registered nurse & 84 & 67 \\
\hline - Practical nurse or emergency medical technician & 15 & 12 \\
\hline \multicolumn{3}{|l|}{ Work experience in years } \\
\hline$\bullet<5$ & 23 & 18 \\
\hline$\cdot 5-10$ & 21 & 17 \\
\hline$\bullet 11-15$ & 21 & 17 \\
\hline$\bullet 16-20$ & 14 & 11 \\
\hline -21-25 & 8 & 6 \\
\hline -26-30 & 13 & 10 \\
\hline$\bullet>30$ & 25 & 20 \\
\hline
\end{tabular}

Comparison by profession did not reveal significant differences in respondents' knowledge of simulation teaching. Figure 2 reveals that the majority of the doctors $(61 \%)$ rated their knowledge as quite weak or moderate. The registered nurses had a similar result, with $62 \%$ of them considering their knowledge to be moderate or quite weak. The figure also shows that the greatest group of practical nurses (43\%) regarded their knowledge as moderate, while an equal proportion of them $(21 \%)$ rated their knowledge as quite good or quite weak. The Kruskal-Wallis test revealed that respondents with the phased-out higher vocational education found their knowledge better compared to participants with the current university of applied sciences education $(p=.070)$. 
The length of work experience did not have a statistically significant effect on respondents' knowledge of simulation teaching.

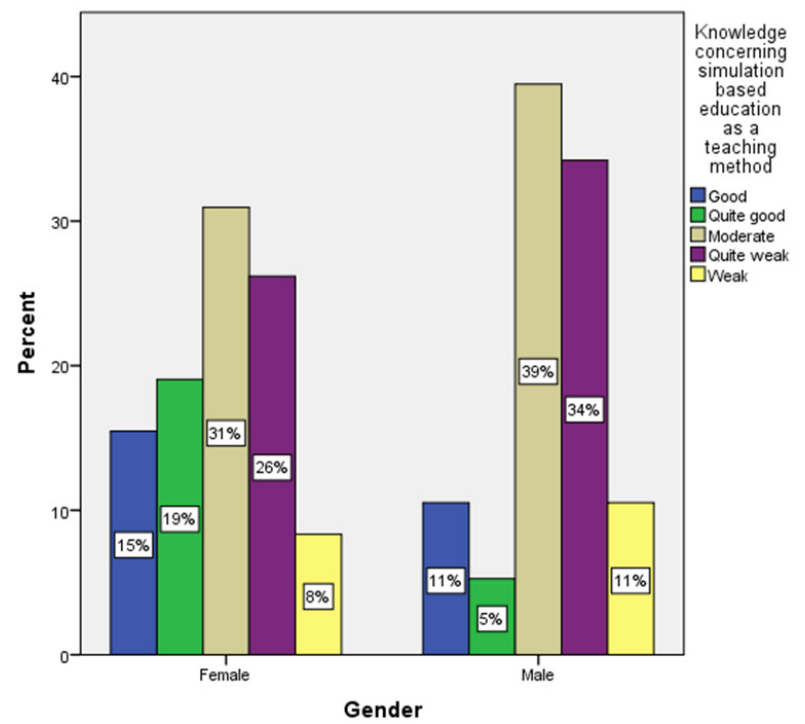

Figure 1. Respondents' knowledge of simulation as a teaching method by gender

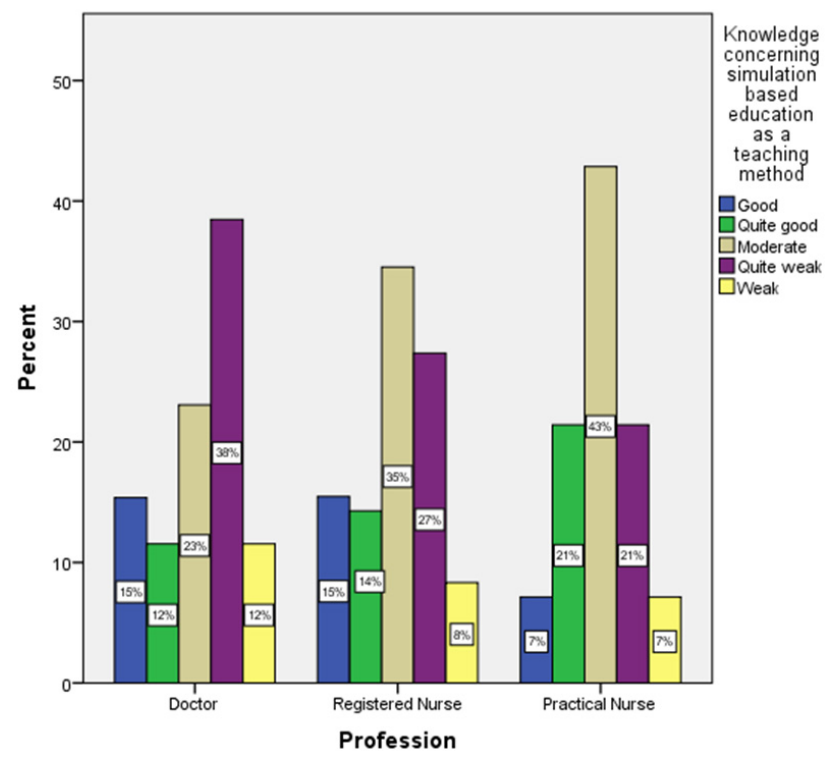

Figure 2. Respondents' knowledge of simulation as a teaching method by profession

\subsection{Nursing and medical staff's knowledge of simulated learning environments}

As shown in Figure 3, the greatest group in both women (38\%) and men (42\%) rated their knowledge of simulated learning environments as moderate. More than a third of the women $(34 \%)$ considered their knowledge good or quite good. In men, however, only $18 \%$ regarded their knowledge of simulated learning environments as good or quite good. Nearly a third of the women (28\%) and $40 \%$ of the men chose the options "weak" or "quite weak" knowledge. Mann-Whitney U test revealed a statistically nearly significant difference in women's and men's knowledge $(p=.077)$; women rated their knowledge as better than men. Comparison by age using the Kruskal-Wallis test also revealed a statistically significant difference $(p=.001)$, showing that the 50-59-year-olds rated their knowledge of simulated learning environments as better than the 30-39-year-olds. It is worth noting that both the 50-59 and 60-69-year-old respondents found their knowledge better than the younger age group.

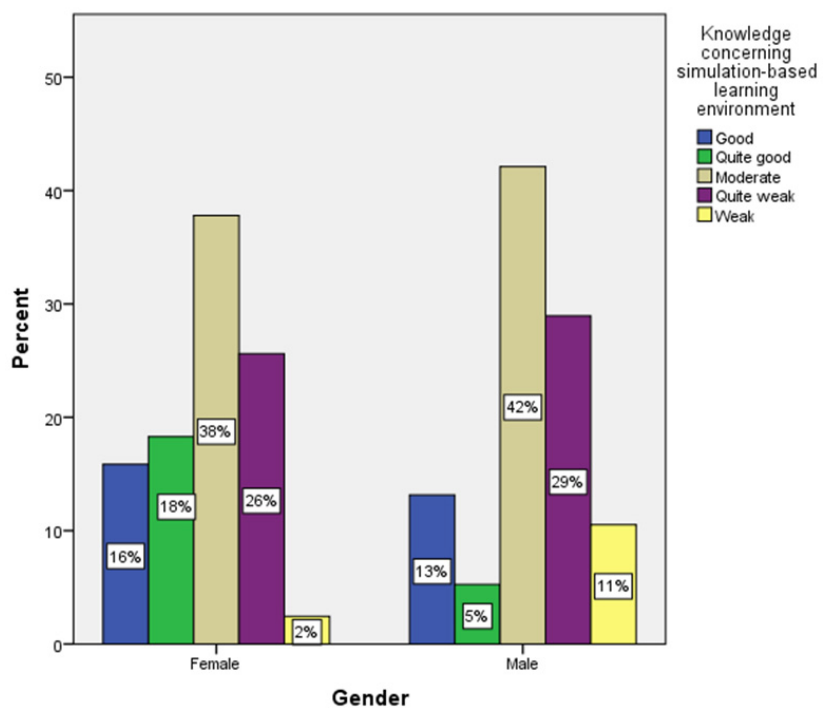

Figure 3. Respondents' knowledge of simulated learning environments by gender

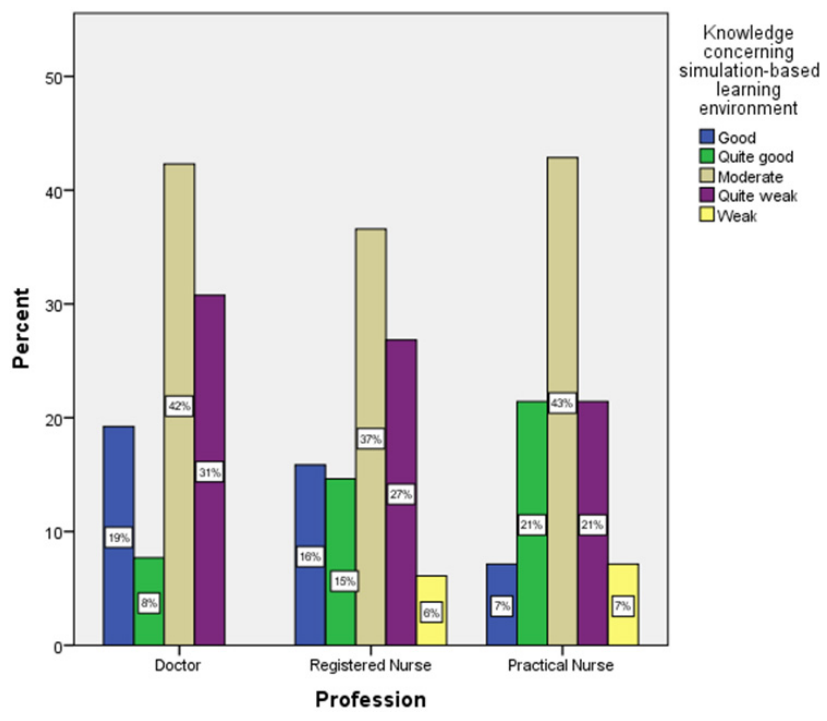

Figure 4. Respondents' knowledge of simulated learning environments by profession 
As Figure 4 showed, there was some variation in doctors', registered nurses' and practical nurses' knowledge of simulated learning environments. A common feature among them was that in all professional groups, the greatest group of respondents rated their knowledge as moderate. In doctors, nearly a third (27\%) claimed that their knowledge of simulated learning environments was good or quite good. In registered nurses, the corresponding proportion was $31 \%$ and in practical nurses $28 \%$. None of the doctors considered their knowledge to be weak, but $31 \%$ chose the option "quite weak". In registered nurses, $27 \%$ and in practical nurses, $21 \%$ of the respondents regarded their knowledge as quite weak. In addition, $6 \%$ of the registered nurses and $7 \%$ of the practical nurses felt that they had weak knowledge of simulated learning environments. The Kruskal-Wallis test revealed that that respondents with the older higher vocational education rated their knowledge higher compared to respondents with the current university of applied sciences education ( $p=.045)$. There was no statistical evidence for an association between work experience and knowledge of simulated learning environments.

\subsection{Nursing and medical staff's experiences of the use- fulness of simulation teaching}

According to the Kruskal-Wallis test, there was a statistically significant difference between doctors and registered nurses; compared to nurses, doctors were more inclined to think that simulation teaching had promoted their learning $(p=.028)$. A statistically significant difference $(p=.08)$ was found between doctors and registered nurses as specifically regards the respondents' experience that simulation teaching had strengthened their practical skills. In this study, $40 \%$ of the doctors claimed that simulation had helped them a lot or quite a lot in learning to encounter and support family members in challenging situations. In contrast, only $19 \%$ of the registered nurses and $20 \%$ of the practical nurses claimed that simulation teaching had facilitated their learning this kind of interaction a lot or quite a lot. It can also be noted that $40 \%$ of the registered nurses and $30 \%$ of the practical nurses felt that simulation had been of little help to them when learning to encounter and support family members. Another statistical difference $(p=.04)$ was discovered between doctors and practical nurses using the Kruskal-Wallis test as regards the usefulness of simulation in learning consistent reporting and informing. In this respect, the doctors found simulated teaching much more useful than practical nurses. Finally, a comparison between respondents' age and perceived usefulness of simulation teaching revealed a significant difference $(p=.037)$ between the under 30-year-olds and the 50-59-year-olds. Respondents in the older age group found simulated teaching more useful in the orientation of new employees than the younger respondents.

Using a Likert scale from 1 to 5, respondents agreed that simulation teaching could strengthen the following skills: theoretical skills (mean 4.94), practical skills (mean 5.22), interaction skills (mean 5.04), teamwork skills (mean 5.31) and management and supervisory skills (mean 4.93). Simulation teaching was considered useful in learning to manage acute care situations (mean 5.33), recurrent care situations (mean 4.67) and infrequent care situations (mean 5.20). Respondents also found that simulation teaching could be useful in orienting new employees (mean 4.70), in multiprofessional continuing education (mean 4.91) and in solving conflicts (mean 3.81) or ethically challenging situations (mean 4.00).

\section{Discussion}

The greatest group in both female (31\%) and male (39\%) respondents in this study rated their knowledge of simulation teaching as only moderate, although $82 \%$ of them had at some point participated in simulation education. The result may be due to the fact that the majority of the respondents had participated in simulation training only a few times. The respondents, who had graduated before the year 2000, had only participated in workplace simulation training on acute situations (trauma team and resuscitation), whereas the respondents, who had graduated after the year 2000, had already during their nursing or medical studies taken part in various workshops, virtual and full scale simulations.

However, it was discovered that the 50-59-year-old nursing staff members rated their knowledge as higher than the 30-39year-olds. The result is of some interest, because simulation had not been part of the healthcare education when members of the older age group were students. It is also unexpected that the under 30-year-olds should find their knowledge of simulation education relatively limited, although simulation has for some time been commonly used in nursing education. Another surprising result is that graduates from the already phased-out higher vocational education rated their knowledge of simulation as higher than graduates with experience of simulated learning in the current nursing programs in universities of applied sciences. The knowledge levels of the older age group might be an indication of good commitment to professional development and work, even when close to retirement age.

Generally, the study confirms earlier findings of simulation as a useful tool in education; the respondents found that simulation teaching had strengthened their theoretical and practical skills. There is much evidence for the effectiveness of simulation-based education in learning both clinical and non-clinical skills. ${ }^{[19]}$ Simulation teaching was considered 
useful in learning to manage acute care situations (mean 5.33), recurrent care situations (mean 4.67) and infrequent care situations (mean 5.20). Respondents also found that simulation teaching could be useful in orienting new employees (mean 4.70), in multiprofessional continuing education (mean 4.91) and in solving conflicts (mean 3.81) or ethically challenging situations (mean 4.00).

Respondents in this study agreed that simulation teaching can promote participants' interaction, teamwork and management and supervisory skills. Respondents also found that simulation education could be used to enhance consistent reporting and informing skills. A finding which can be considered interesting from the viewpoint of developing patient care is that the doctors in this study found simulation much more useful in learning to encounter and support families than nursing staff members. One might speculate if the result is associated with the fact that compared to medical studies, nursing education has traditionally placed a stronger emphasis on learning interaction skills. Secondly, that the idea pointed out in earlier research ${ }^{[36]}$ that socialization by separate education leads to communication gaps across professions might be relevant for this study as well. In any case, research has shown that simulated learning can enhance interaction skills and it has been found especially useful for team building. ${ }^{[2,37-40]}$ Simulation can help professional groups become aware of each other's competence and responsibilities ${ }^{[19]}$ and it has shown communication improvement within and between health care professions. ${ }^{[41]}$ Earlier research also suggests that simulation pedagogy can be useful in practicing informing, reporting and consultation in order to promote multiprofessional collaboration and pa- tient safety. ${ }^{[42,43]}$ Simulated training has been recommended for developing situational sensitivity and problem-solving skills to prevent near misses. ${ }^{[44,45]}$

\section{Conclusions}

Based on the results it can be concluded that the nursing and medical staff of the hospital district involved in this study need more information about simulation education and simulated learning environments. The result might be partly explained by the limited number of respondents. Both groups in this study, however, found simulation teaching useful for their theoretical and practical competence. The great number of staff combined with the current economic constraints means that individual employees can seldom participate in continuing education programs outside their workplace. This makes the current project all the more important. It brings together a university of applied sciences, a vocational education center, a health technology development center and a hospital district that provides specialized medical services in Finland, in order to create a network of simulation experts and to provide multiprofessional continuing education. The descriptive knowledge produced in this study can be used in planning the education for nursing and medical staff. Simulation pedagogy can be especially useful when practicing teamwork and interaction in acute, recurring and infrequent care situations. Simulation based education can also increase professional group's awareness of each others' competence and responsibilities, which in turn can promote patient safety.

\section{CONFLicts OF INTEREST Disclosure}

The authors declare they have no conflicts of interest.

\section{REFERENCES}

[1] Hayden JK, Smiley RA, Alexander M, et al. The NCSBN National simulation study: A longitudinal, randomized, controlled study replacing clinical hours with simulation in prelicensure nursing education. JoR. 2014; 5(2): 3-64.

[2] Marshall SD, Flanagan B. Simulation-based education for building clinical teams. J Emerg Trauma Shock. 2010 Oct-Dec; 3(4): 360-8. https://doi.org/10.4103/0974-2700.70750

[3] March AL, Adams MH, Robinson C. Student characteristics and perceptions of learning and confidence acquisition associated with simulation. Nurs Educ Perspect. 2014; 35(5): 335-6. PMid: 25291932. https://doi.org/10.5480/12-998.1

[4] McCallin A. Interdisciplinary practice - a matter of teamwork: an integrated literature review. J Clin Nurs. 2001; 10: 419-28. PMid: 11822488. https://doi.org/10.1046/j.1365-2702.2001.0 0495.x

[5] McPherson K, Headrick L, Moss F. Working and learning together: good quality care depends on it, but how can we achieve it? Qual Health Care. 2001; 10(11): ii46-53. https://doi.org/10.1136/ qhe. 0100046

Published by Sciedu Press
[6] Milkins L, Moore C, Spiteri J. Simulation based education. Professional entry student education and training. Networks, Simulation and Supervision (HETI). 2014. Available from: www . heti .nsw . gov . au

[7] Hansen J, Bratt M. Competence acquisition using simulated learning experiences: a concept analysis. Nurs Educ Perspect. 2015; 36(2): 102-7. https://doi.org/10.5480/13-1198

[8] Kettunen N. Simulaatio-opetus terveysalan koulutuksessa. Ammattikorkeakouluopettajien kokemuksia [Simulation in health care education: teachers' experiences in the university of applied sciences, Bachelor's thesis]. Metropolia University of Applied Sciences; 2014. 66 p. Available from: http://urn.fi/URN: NBN : fi: amk-2014112817359

[9] Beaubien JM, Baker DP. The use of simulation for training teamwork skills in health care: how low can you go? Qual Saf Health Care. 2004; 13(1): i51-6. PMid: 15465956. https://doi.org/10.113 6/qshc. 2004.009845

[10] Corrigan JM, Kohn LT, Donaldson MS. To err is human: building a safer health service. Washington D.C.: National Academy Press; 2000. 
[11] Gaba D. Anaesthesiology as a model for patient safety in health care. Br Med J. 2000; 320(7237): 785-8. https://doi.org/10.1136/ bmj.320.7237.785

[12] Sørensen JL, Østergaard D, LeBlanc V, et al. Design of simulationbased medical education and advantages and disadvantages of in situ simulation versus off-site simulation. BMC Med Educ. 2017; 17(20): 1-9. https://doi.org/10.1186/s12909-016-0838-3

[13] Sørensen JL, LØkkegaard E, Johansen M, et al. The implementation and evaluation of a mandatory multi-professional obstetric skills training program. Acta Obstet Gynecol Scand. 2009; 88(10): 1107 1117. PMid: 19688616. https://doi.org/10.1080/00016340 903176834

[14] Andersen PO, Jensen MK, Lippert A, et al. Development of a formative assessment tool for measurement of performance in multiprofessional resuscitation teams. Resuscitation. 2010; 81(6): $703-$ 711. PMid: 20346566. https://doi.org/10.1016/j.resuscit ation. 2010.01 .034

[15] Markova V, Sørensen JL, Holm C, et al. Evaluation of multiprofessional obstetric skills training for postpartum hemorrhage. Acta Obstet Gynecol Scand. 2012; 91(3): 346-52. PMid: 22171606 https://doi.org/10.1111/j.1600-0412.2011.01344.x

[16] Fransen AF, Banga FR, van de Ven J, et al. Multi-professional simulation-based team training in obstetric emergencies for improving patient outcomes and trainees' performance (Protocol). Cochrane Database Syst Rev. 2015; 2: 1-11.

[17] Ross AJ, Reedy GB, Roots A, et al. Evaluating multisite multiprofessional simulation training for a hyperacute stroke service using the Behaviour Change Wheel. BMC Med Educ. 2015; 15(143): 1-10. https://doi.org/10.1186/s12909-015-0423-1

[18] Sørensen JL, Thellesen L, Strandbygaard J, et al. Development of knowledge tests for multi-disciplinary emergency training: a review and an example. Acta Anaesthosiol Scand. 2015; 59(1): 123-33. PMid: 25363488. https://doi.org/10.1111/aas. 12428

[19] Vanhanen M, Hyvämäki P, Varkki E, et al. Kokemuksia moniammatillisesta tehohoidon simulaatiokoulutuksesta [Experiences of multiprofessional simulation education in intensive care]. Tehohoito. 2017; 35(1): 1-5.

[20] Cook DA. How much evidence does it take? A cumulative metaanalysis of outcomes of simulation-based education. Med Educ. 2014; 48: 750-60. PMid: 25039731. https ://doi .org/10.1111/medu .12473

[21] Brydges R, Hatala R, Zendejas B, et al. Linking simulation-based educational assessments and patient-related outcomes: a systematic review and meta-analysis. Acad Med. 2015; 90: 246-56. PMid: 25374041. https://doi.org/10.1097/ACM. 00000000000005 49

[22] Cheng A, Grant V, Auerbach M. Using simulation to improve patient safety: dawn of a new era. JAMA Pediatr. 2015; 169: 419 20. PMid: 25751767. https://doi.org/10.1001/jamapediat rics. 2014.3817

[23] Baillie L, Curzio J. Students' and facilitators' perceptions of simulation in practice learning. Nurse Educ Pract. 2009; 9(5): $297-$ 306. PMid: 18842463. https://doi.org/10.1016/j.nepr.2 008.08 .007

[24] Cook DA, Hatala R, Brydges R, et al. Technology-enhanced simulation for health professions education: a systematic review and meta-analysis. JAMA. 2011; 306(9): 978-88. PMid: 21900138. https://doi.org/10.1001/jama.2011.1234

[25] Cook DA, Brydges R, Zendejas B, et al. Comparative effectiveness of instructional design features in simulation-based education: Systematic review and meta-analysis. Med Teach. 2013; 35(1): e867-98.
PMid: 22938677. https ://doi.org/10.3109/0142159X. 2012. 714886

[26] Adamson K. A systematic review of the literature related to the NLN/Jeffries Simulation Framework. Nurs Educ Perspect. 2015; 36(5): 281-91. PMid: 26521495. https://doi.org/10.5480/15 $-1655$

[27] Cooper S, Cant R, Porter J, et al. Simulation based learning in midwifery education: A systematic review. Women Birth. 2012; 25(2): 64-78. PMid: 21489894. https ://doi.org/10.1016/j . wombi. 2011.03 .004

[28] LaFond CM, Vincent HV. A critique of the National League for Nursing/Jeffries Simulation Framework. J Adv Nurs. 2012; 69(2): 465-80. PMid: 22715857. https://doi.org/10.1111/j.1365 $-2648.2012 .06048 . \mathrm{x}$

[29] Baker DP, Day R, Salas E. Teamwork as an essential component of high reliability organizations. Health Serv Res. 2006; 41: $1577-$ 98. PMid: 16898980. https://doi.org/10.1111/j.1475-677 3.2006.00566. $\mathrm{x}$

[30] Webropol Survey and Analysis Tool. Haka Federation. 2017. Available from: https://www. webropolsurveys.com/Shibboleth /HakaLogin.aspx

[31] Heikkilä T. Tilastollinen tutkimus [Statistical research]. $9^{\text {th }}$ ren. ed. Helsinki: Edita Publishing Oy; 2014.

[32] Burns N, Grove SK. The practice of nursing research: appraisal, synthesis and generation of evidence. $7^{t h}$ ed. Philadelphia: W.B. Saunders Company; 2012.

[33] TENK. Finnish Advisory Board on Research Integrity. Responsible conduct of research and procedure for handling allegations of misconduct in Finland. Guidelines of the Finnish Advisory Board on Research Integrity 2012. 2017. Available from: http://www.tenk .fi/sites/tenk.fi/files/HTK_ohje_2012.pdf

[34] Polit DF, Beck CT. Nursing research: generating and assessing evidence for nursing practice. Philadelphia: Wolters Kluwer Health/Lippincott Williams \& Wilkins; 2011.

[35] Shih TH, Fan X. Comparison response rates in e-mail and paper surveys: A meta-analysis. Educ Res Rev. 2009; 4(1): 26-40. https ://doi.org/10.1016/j.edurev.2008.01.003

[36] Velji K, Baker GR, Fancott C, et al. Effectiveness of an adapted SBAR communication tool for a rehabilitation setting. Healthc Q 2008; 11: 72-9. PMid: 18382165. https://doi.org/10.12927 /hcq. 2008. 19653

[37] Eggenberger SK, Regan M. Expanding simulation to teach family nursing. J Nurs Educ. 2010; 49(10): 550-8. PMid: 20672781. https : //doi.org/10.3928/01484834-20100630-01

[38] Eggenberger SK, Krumwiede NK, Young PK. Using simulation pedagogy in the formation of family-focused generalist nurses. J Nurs Educ. 2015 Oct; 54(10): 588-93. https ://doi.org/10.3928/01 484834-20150916-08

[39] Berragan E. Simulation: An effective pedagogical approach for nursing? Nurse Educ Today. 2011; 31(7): 660-3. Available from: http://eprints.uwe.ac.uk/20108

[40] Berragan E, Short H, Grindrod E. Using simulation pedagogy in nursing to enhance learning through assessment. In: NET2015, Cambridge; 2015. Available from: http://eprints.uwe.ac.uk/28 077

[41] Kenaszchuk C, MacMillan K, van Soeren M, et al. Interprofessional learning: Short term associations between simulation and interprofessional collaboration. BMC Med. 2011; 9(29): 1-10. https ://doi .org/10.1186/1741-7015-9-29

[42] Issenberg SB, Mcgaghic WC, Petrusa ER, et al. Features and uses of high-fidelity medical simulations that lead to effective learning: 
a BEME systematic review. Med Teach. 2005; 27: 10-28. PMid: 16147767. https://doi.org/10.1080/01421590500046924

[43] Jeffries PR. Signs of maturity. Simulations are growing and getting more attention. Nurs Educ Perspect. 2015; 36(6): 358-9. https: //doi.org/10.5480/1536-5026-36.6.358

[44] Duff B. Creating a culture of safety by coaching clinicians to compe- tence. Nurse Educ Today. 2013; 33(10): 1108-11. PMid: 22726347. https://doi.org/10.1016/j.nedt.2012.05.025

[45] Forneris SG, Neal DO, Tiffany J, et al. Enhancing clinical reasoning through simulation debriefing: a multisite study. Nurs Educ Perspect. 2015; 36(5): 304-10. PMid: 26521499. https ://doi.org/10.5 $480 / 15-1672$ 